\title{
Noninvasive Assessment of Autonomic Cardiovascular Function in Patients after Arterial Switch Operation for Transposition of the Great Arteries
}

\author{
Joanna Hlebowicz ${ }^{1,2}$, Maja Rooth ${ }^{3}$, Sandra Lindstedt ${ }^{4}$, Johan Holm², Ulf Thilén ${ }^{2}$ \\ ${ }^{1}$ Department of Internal Medicine, Skåne University Hospital, Lund University, Malmö, Sweden \\ ${ }^{2}$ Department of Cardiology, Skåne University Hospital, Lund University, Lund, Sweden \\ ${ }^{3}$ Lund University, Malmö, Sweden \\ ${ }^{4}$ Department of Cardiothoracic Surgery, Skåne University Hospital, Lund University, Lund, Sweden \\ Email: *joanna.hlebowicz@med.lu.se
}

Received 16 February 2015; accepted 11 March 2015; published 12 March 2015

Copyright (C) 2015 by authors and Scientific Research Publishing Inc.

This work is licensed under the Creative Commons Attribution International License (CC BY).

http://creativecommons.org/licenses/by/4.0/

(c) (i) Open Access

\begin{abstract}
Background: Children born with transposition of the great arteries (TGA) must undergo corrective surgery for survival, arterial switch being the standard surgical procedure. The sympathetic innervation of the heart may be damaged during the operation. This study was designed to determine whether adults who were born with TGA and who had arterial switch operation (ASO) in infancy exhibit denervation of the heart, measured as heart rate variability (HRV) with electrocardiography (ECG). Methods: Nine patients with transposition of the great arteries (four men and five women; mean age $26 \pm 1$ years) who underwent the ASO at mean age of $85 \pm 35$ days, and nine healthy adults (five men and five women; mean age $26 \pm 2$ ) were included in the study. Cardiac autonomic nerve function was determined by the variation in RR intervals during maximal deep breathing, monitored by continuous ECG. The mean values were calculated for each group from six inspirations (I) and expirations (E), and the E:I ratios were calculated. Results: The E:I ratio did not differ between patients with an arterial switch and healthy controls $(P=0.161)$. Two patients had signs of denervation of the heart up to 30 years after the arterial switch operation. Conclusions: Reinnervation of the heart may take place in patients who have undergone the ASO in infancy, and these patients would not necessarily suffer from autonomic dysfunction. The HRV, measured by ECG, has the potential to identify arterially switched patients at risk of developing silent myocardial ischemia.
\end{abstract}

${ }^{*}$ Corresponding author.

How to cite this paper: Hlebowicz, J., Rooth, M., Lindstedt, S., Holm, J. and Thilén, U. (2015) Noninvasive Assessment of Autonomic Cardiovascular Function in Patients after Arterial Switch Operation for Transposition of the Great Arteries. Surgical Science, 6, 126-132. http://dx.doi.org/10.4236/ss.2015.63020 


\section{Keywords}

\section{Congenital Heart Disease, Transposition of the Great Arteries, Arterial Switch Operation, Sympathetic Innervation}

\section{Introduction}

Transposition of the great arteries (TGA), i.e. the aorta and pulmonary artery, is one of the most common cyanotic congenital heart malformations [1]. The systemic and pulmonary circulatory systems function in parallel, and communication between them is vital, at an atrial, ventricular or aorto-pulmonary level. Children born with complete TGA have to undergo corrective surgery to survive [2]. The arterial switch operation (ASO), first described by Jatene in 1976, in which the great arteries and the coronary arteries are transected and translocated, is nowadays the standard procedure [3]. This operation results in suture lines across the ascending aorta and pulmonary trunk, as well as around the coronary ostia [4]. It has been shown in animal models that the autonomous innervation of the heart is damaged in the immediate postoperative period following an arterial switch operation [5]. By means of a radiopharmaceutical metaiodobenzylguanidine, denervation of the heart has been found early after the ASO. Although reinnervation of various degrees took place later, this was much more frequent if surgery was performed before 55 days of age [6]. However, radiation exposure should be avoided, especially in children.

In 1979, Sundkvist et al. showed that measuring the difference of the R-R interval on an electrocardiographic recording during deep inspiration and expiration was effective in revealing autonomic nervous dysfunction in patients suffering from diabetes mellitus [7]. It is dependent on age, but not on resting heart rate [8]. Heart rate variability (HRV) analysis is clinically used to predict the risk of arrhythmic events or sudden cardiac death, and as a clinical marker of evolving diabetic neuropathy [9]. The relative risk of silent myocardial ischemia and mortality is doubled in diabetic patients with autonomic neuropathy, defined as decreased HRV [10]. Absence of angina after heart transplantation is believed to be due to ventricular denervation by the surgical procedure [11]. Heart transplanted patients have an impaired heart rate response to exercise due to denervation [12]. However, partial sympathetic reinnervation has been reported after heart transplantation [13] [14].

In the long-term, the main causes of death in patients with TGA who have had ASO seem to be myocardial ischemia and sudden death [15]-[20]. Efficient screening is thus important, especially since patients with denervated hearts may not experience any symptoms of myocardial ischemia. This study was designed to determine whether adults who had previously undergone ASO in infancy due to TGA exhibited denervation of the heart, measured as HRV.

\section{Subjects and Methods}

Nine patients with TGA who underwent an arterial switch operation between 1977 and 1992 were included in this study (four men and five women; mean age at inclusion $26 \pm 1$ years; mean body mass index at inclusion $26.9 \pm 5.6 \mathrm{~kg} / \mathrm{m}^{2}$; operated on at a mean age of $85 \pm 35$ days). Four of the nine patients had ASO before two weeks of age. In three cases there was an associated ventricular septal defect, which was repaired at the time of the arterial switch operation. One patient had a late reoperation for pulmonary stenosis (Table 1). No patients used any medication. Hospital level: Tertiary centre for congenital heart disease in children and adults. Catchment area 2 - 5 millions inhabitants depending on issue. One of two national centres for congenital cardiac surgery, more than 300 cases yearly grown up congenital heart (GUCH) outpatient clinic nearly 1000 visits/year. Nine healthy controls matched for age and sex (four men and five women; mean age $26 \pm 2$ years; mean body mass index $22.4 \pm 1.5 \mathrm{~kg} / \mathrm{m}^{2}$ ) were also recruited (Table 2). All measurements were performed with the subjects in light clothing without shoes. The body weight was measured to the nearest $0.1 \mathrm{~kg}$ and the height to the nearest $\mathrm{cm}$ and the BMI calculated.

Cardiac autonomic nerve function was determined by the variation in $\mathrm{R} \pm \mathrm{R}$ intervals during maximal deep breathing, monitored by continuous electrocardiography (ECG) [7]. All subjects were examined once, in a random order, between June 7 and July 3, 2012, at the Skåne University Hospital, in Malmö, Sweden. A normal resting ECG was first obtained, after which the subjects were given instructions for the deep-breathing test. After 
Table 1. Characteristics of nine patients with transposition of the great arteries who underwent an arterial switch operation between 1977 and 1992.

\begin{tabular}{|c|c|c|c|c|c|c|c|c|c|}
\hline Patient & Age & Gender & BMI & Heart rate & $\mathbf{E}$ & $\mathbf{I}$ & E:I ratio & Type of operation & Age at operation \\
\hline & (years) & & $\left(\mathrm{kg} / \mathrm{m}^{2}\right)$ & (beats/min) & $(\mathrm{mm})$ & $(\mathrm{mm})$ & & & \\
\hline \multirow[t]{3}{*}{1} & 21 & Female & 21.5 & 71 & 54.7 & 36.8 & 1.49 & BAS & 1 day \\
\hline & & & & & & & & PDA closure & 6 days \\
\hline & & & & & & & & Arterial switch & 6 days \\
\hline \multirow[t]{6}{*}{2} & 24 & Female & 26.7 & 73 & 43.7 & 38.0 & 1.15 & BAS & 5 days \\
\hline & & & & & & & & PDA closure & 13 days \\
\hline & & & & & & & & Pulmonary banding & 13 days \\
\hline & & & & & & & & VSD closure (suture) & 5 months \\
\hline & & & & & & & & Arterial switch & 5 months \\
\hline & & & & & & & & VSD closure (patch) & 5 months \\
\hline \multirow[t]{2}{*}{3} & 23 & Male & 23.3 & 61 & 64.6 & 38.0 & 1.68 & BAS & 1 day \\
\hline & & & & & & & & Arterial switch & 11 days \\
\hline 4 & 25 & Male & 24.2 & 73 & 44.4 & 38.3 & 1.16 & Arterial switch & 1 month \\
\hline \multirow[t]{4}{*}{5} & 24 & Female & 30.9 & 74 & 41.9 & 35.3 & 1.19 & ASD closure (suture) & 1.5 months \\
\hline & & & & & & & & PDA closure & 1.5 months \\
\hline & & & & & & & & VSD closure (patch) & 1.5 months \\
\hline & & & & & & & & Arterial switch & 1.5 months \\
\hline \multirow[t]{3}{*}{6} & 31 & Female & 25.3 & 77 & 39.0 & 36.8 & 1.07 & BAS & 1 day \\
\hline & & & & & & & & Arterial switch & 6 months \\
\hline & & & & & & & & PDA closure & 6 months \\
\hline \multirow[t]{5}{*}{7} & 27 & Male & 39.8 & 81 & 37.3 & 35.4 & 1.05 & BAS & 2 days \\
\hline & & & & & & & & VSD closure (patch) & 3 months \\
\hline & & & & & & & & Arterial switch & 3 months \\
\hline & & & & & & & & $\begin{array}{l}\text { Balloon dilatation of supravalv. } \\
\text { pulm. stenosis }\end{array}$ & 22 years \\
\hline & & & & & & & & $\begin{array}{l}\text { Surgical reconstruction of } \\
\text { pulmonary trunk }\end{array}$ & 22 years \\
\hline \multirow[t]{2}{*}{8} & 35 & Male & 26.9 & 63 & 52.3 & 48.0 & 1.09 & BAS & 3 months \\
\hline & & & & & & & & Arterial switch & 11 months \\
\hline \multirow[t]{2}{*}{9} & 23 & Female & 23.3 & 62 & 51.2 & 38.4 & 1.33 & BAS & 1 day \\
\hline & & & & & & & & Arterial switch & 6 days \\
\hline
\end{tabular}

E:I, expiration:inspiration; BMI, body mass index; BAS, balloon atrioseptostomy; ASD, atrial septal defect; VSD, ventricular septal defect; PDA, persistent ductus arteriousus.

30 minutes' rest in the supine position, the subjects' heart rates were checked before they underwent continuous ECG recording for $1 \mathrm{~min}$, while performing six maximal deep-breathing maneuvers. The examiner first demonstrated six maximal deep breaths lasting approximately $5 \mathrm{~s}$ in and $5 \mathrm{~s}$ out, and the patients then practiced for 1 min before the actual deep breathing tests. During the ECG recording, the subject was instructed when to breathe in and out. The shortest $\mathrm{R} \pm \mathrm{R}$ intervals during inspiration and the longest during expiration were determined. The mean values were calculated from the six inspirations (IR $\pm R$ mean) and expirations ( $E R \pm R$ mean), and the E:I ratios were calculated as $\mathrm{ER} \pm \mathrm{R}$ mean/IR $\pm \mathrm{R}$ mean. The test was performed twice, and the mean of 
Table 2. Characteristics of nine healthy controls matched for age and sex.

\begin{tabular}{|c|c|c|c|c|c|c|c|}
\hline Healthy control & Gender & Age & BMI & Heart rate & I & $\mathrm{E}$ & E:I ratio \\
\hline & & (years) & $\left(\mathrm{kg} / \mathrm{m}^{2}\right)$ & (beats/min) & $(\mathrm{mm})$ & $(\mathrm{mm})$ & \\
\hline 1 & Male & 38 & 31.1 & 64 & 36.8 & 32.5 & 1.13 \\
\hline 2 & Male & 27 & 22 & 92 & 38.0 & 29.1 & 1.32 \\
\hline 3 & Female & 22 & 20.7 & 48 & 72.3 & 57.6 & 1.26 \\
\hline 4 & Female & 25 & 18.4 & 76 & 44.7 & 36.8 & 1.26 \\
\hline 5 & Female & 24 & 17.7 & 67 & 49.3 & 33.7 & 1.46 \\
\hline 6 & Male & 23 & 20.4 & 54 & 60.0 & 36.8 & 1.63 \\
\hline 7 & Female & 31 & 27.8 & 67 & 55.8 & 38.3 & 1.46 \\
\hline 8 & Male & 25 & 24.5 & 54 & 64.4 & 45.0 & 1.43 \\
\hline 9 & Female & 22 & 19.2 & 68 & 49.3 & 36.6 & 1.35 \\
\hline
\end{tabular}

E:I, expiration:inspiration, BMI, body mass index.

the two E:I ratios obtained from the tests was calculated for each individual. A mean E:I ratio $>1.18$ was considered normal, 1.18 - 1.09 borderline, and $<1.09$ abnormal [7] [21].

All subjects gave their written informed consent to participation in the study. The study was approved by the Ethics Committee at Lund University, and performed according to the Helsinki Declaration.

\section{Statistical Analysis}

Results are given as mean values and the standard error on the mean, unless otherwise stated. All statistical calculations were performed in PASW Statistics (SPSS Statistics, version 18, 2009). The significance in differences between a given parameter in the TGA patients and healthy controls was determined using the Mann-Whitney U test. The level of statistical significance was set at $P<0.05$.

\section{Results}

The mean heart rate in the nine patients who had undergone arterial switch operation was $71 \pm 2$, compared to $66 \pm 4$ in the healthy controls (Table 1 , Table 2 ). The difference was not statistically significant $(P=0.297$ ). The mean $\mathrm{E}$ and $\mathrm{I}$ in the nine patients who had undergone arterial switch operation were $47.7 \pm 2.9$ and $38.3 \pm$ 1.3, compared to $52.3 \pm 4.0$ and $38.5 \pm 2.8$, in the healthy controls (Table 1, Table 2). The difference was not statistically significant $(P=0.489, P=0.436)$. The mean $\mathrm{E}$ :I ratio in the nine patients who had undergone arterial switch operation was $1.25 \pm 0.07$, compared to $1.37 \pm 0.05$ in the healthy controls (Table 1, Table 2). The difference was not statistically significant $(P=0.116)$. Four of the patients and one of the healthy controls had a borderline E:I ratio (Table 2). Two of the patients had an abnormal E:I ratio (Figure 1, Figure 2, Table 1).

\section{Discussion}

The primary objective of this study was to determine whether patients born with TGA who had undergone an ASO in infancy suffer from autonomic dysfunction of the heart. No significant difference in cardiac autonomic nerve function was seen between the TGA patients and healthy controls. The absence of any significant difference in E:I ratio between the groups may, however, has been due to small numbers of subjects in the study.

The autonomic innervation of the heart is divided into the parasympathetic and sympathetic systems. The parasympathetic innervation derives from the vagus nerve, whose cell bodies (the nucleus ambiguus, nucleus dorsalis and tractus solitarius) are found in the brainstem. The vagus nerve consists of $20 \%$ efferent fibers and $80 \%$ afferent sensory fibers, which transmit information to the brain. Sympathetic stimulation increases heart rate (positive chronotropy), inotropy and conduction velocity (positive dromotropy), whereas parasympathetic stimulation of the heart has the opposite effects. Changes in heart rate, HRV, and blood pressure are some of the 


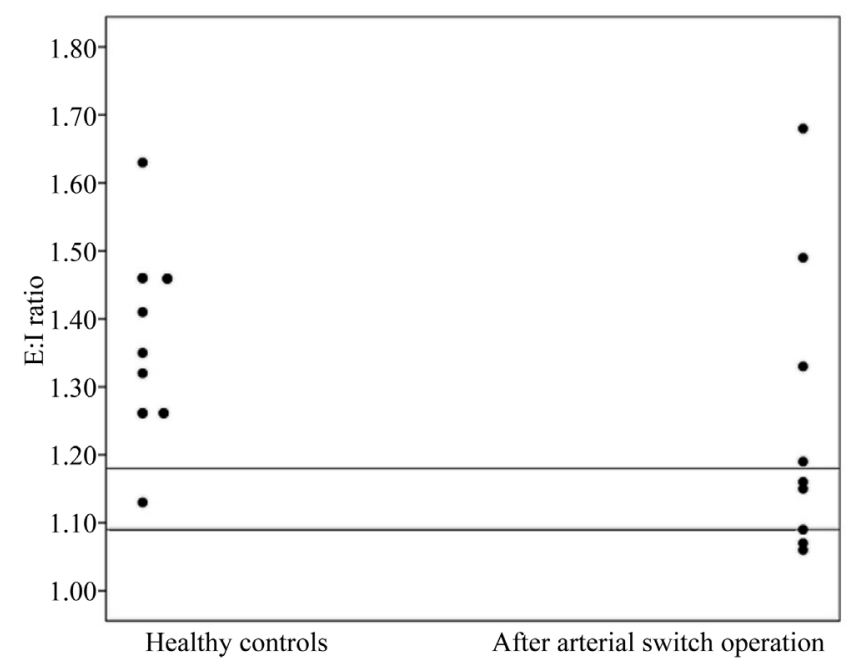

Figure 1. Mean ( \pm SEM) expiration and inspiration (E:I) ratios in nine patients born with transposition of the great arteries, after arterial switch operation, and nine healthy subjects. No significant differences were found between the groups, $P=0.116$ (using the Mann-Whitney U test).

Patient 6

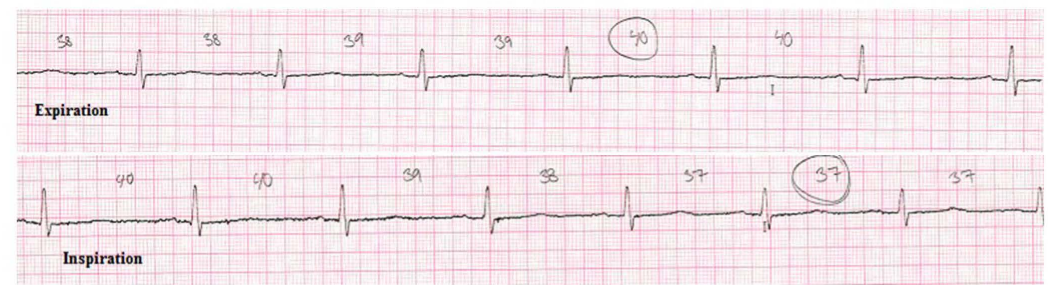

Patient 7
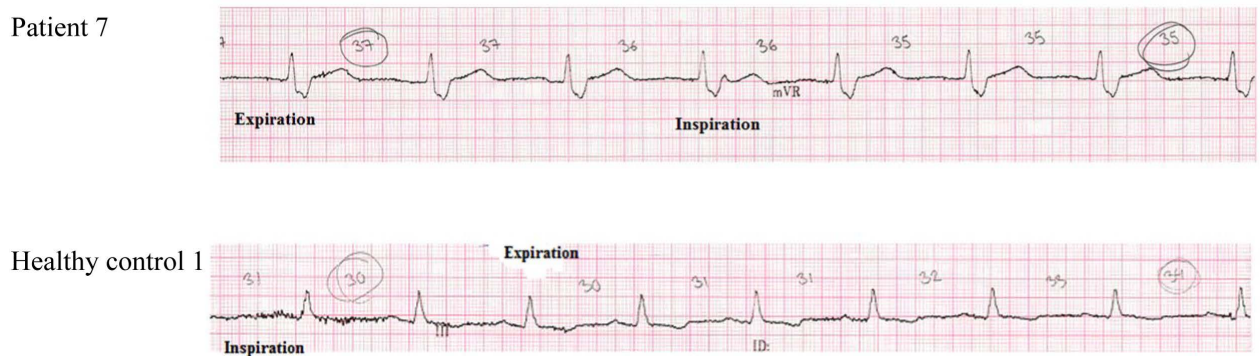

Figure 2. Continuous electrocardiography (ECG) showing examples of the shortest $\mathrm{R} \pm \mathrm{R}$ intervals during inspiration and the longest during expiration in patient $\mathrm{nr} 6,7$ and healthy control $\mathrm{nr} 1$.

variables that may reflect alterations in the balance between the sympathetic and parasympathetic nervous systems. Sympathetic denervation after TGA has been found early after the ASO, and reinnervation late after the surgery, using metaiodobenzylguanidine [6]. However, HRV is currently the method of choice for clinical assessment of denervation of the heart. It is considerably less expensive than scintigraphy and involves no exposure to ionizing radiation. Therefore, HRV would be more suitable for widespread application and repeated measurements.

Coronary complication is a serious clinical problem in patients who have had the ASO, and has been associated with late death [15]-[18]. However, late death generally occurs during childhood and is exceedingly rare in adulthood [15]-[20]. Nevertheless, we cannot assume that the problem disappears when childhood is over. The potential for silent myocardial ischemia in this setting, emphasis on the need for efficient screening for coronary complications, and routine coronary angiography has been suggested during adolescence and/or adulthood to be a part of the long-term follow-up [19] [20]. However, efficient screening is important, especially 
since patients with denervated hearts may not experience any symptoms of myocardial ischemia. Since radiation exposure should be avoided, especially in children, the HRV, measured by ECG, has the potential to identify arterially switched patients at risk of developing silent myocardial ischemia.

We found no significant difference in heart HRV between the patients who had had an arterial switch and the controls in this study. This could indicate that there may be a degree of reinnervation of the heart after ASO procedure, and that the patients will not necessarily suffer from autonomic dysfunction. However, two patients showed signs of denervation of the heart even 30 years after the ASO. This was consistent with the results of a previous study by Kondo et al. A denervation of the heart was found early after the ASO and a reinnervation of various degrees later [6]. The present study had some limitations: the small sample size and the HRV which was only measured long time after the surgery. However, we believe that HRV obtained by ECG during inspiration and expiration, in this setting, has a potential to identify patients at risk of developing silent myocardial ischemia, and our data support the concept that there may be various degrees of cardiac reinnervation in the long-term in patients who have undergone the arterial switch procedure.

\section{Acknowledgements}

The authors' contributions were as follows: Joanna Hlebowicz, Johan Holm, and Ulf Thilén contributed to the design of the study; Joanna Hlebowicz and Maja Rooth were responsible for recruiting the subjects; Maja Rooth carried out the practical aspects of the study. Joanna Hlebowicz performed the statistical calculations; Maja Rooth and Joanna Hlebowicz wrote the first draft of the manuscript, Ulf Thilén and Sandra Lindstedt critically reviewed the manuscript. All authors read and approved the final manuscript. None of the authors have any personal or financial conflicts of interest.

\section{References}

[1] Levin, D.L., Paul, M.H., Muster, A.J., Newfeld, E.A. and Waldman, J.D. (1977) d-Transposition of the Great Vessels in the Neonate: A Clinical Diagnosis. Archives of Internal Medicine, 137, 1421-1425. http://dx.doi.org/10.1001/archinte.1977.03630220061015

[2] Bonchek, L.I. and Star, A. (1972) Total Correction of in Infancy as Initial Surgical Management. Annals of Thoracic Surgery, 14, 376-389. http://dx.doi.org/10.1016/S0003-4975(10)65244-7

[3] Jatene, A.D., Fontes, V.F., Paulista, P.P., Souza, L.C., Neger, F., Galantier, M. and Sousa, J.E. (1976) Anatomic Correction of Transposition of the Great Vessels. Journal of Thoracic and Cardiovascular Surgery, 72, 364-370.

[4] Warners, C.A. (2006) Transposition of the Great Arteries. Circulation, 114, 2699-2709. http://dx.doi.org/10.1161/CIRCULATIONAHA.105.592352

[5] Falkenberg, C., Hallhagen, S., Nilsson, K., Nilsson, B. and Ostman-Smith, I. (2010) A Study of the Physiological Consequences of Sympathetic Denervation of the Heart Caused by the Arterial Switch Procedure. Cardiology in the Young, 20, 150-158. http://dx.doi.org/10.1017/S1047951109990643

[6] Kondo, C., Nakazawa, M., Momma, K. and Kusakabe, K. (1998) Sympathetic Denervation and Reinnervation after Arterial Switch Operation for Complete Transposition. Circulation, 23, 2414-2419. http://dx.doi.org/10.1161/01.CIR.97.24.2414

[7] Sundkvist, G., Almer, L.O. and Lilja, B. (1979) Respiratory Influence on Heart Rate in Diabetes Mellitus. British Medical Journal, 1, 924-925. http://dx.doi.org/10.1136/bmj.1.6168.924

[8] Smith, S.A. (1982) Reduced Sinus Arrhythmia in Diabetic Autonomic Neuropathy: Diagnostic Value of an Age-Related Normal Range. British Medical Journal, 285, 1599-1601. http://dx.doi.org/10.1136/bmj.285.6355.1599

[9] Stys, A. and Stys, T. (1998) Current Clinical Applications of Heart Rate Variability. Clinical Cardiology, 21, $719-724$. http://dx.doi.org/10.1002/clc.4960211005

[10] Maser, R.E., Mitchell, B.D., Vinik, A.I. and Freeman, R. (2003) The Association between Cardiovascular Autonomic Neuropathy and Mortality in Individuals with Diabetes: A Meta-Analysis. Diabetes Care, 26, 1895-1901. http://dx.doi.org/10.2337/diacare.26.6.1895

[11] Bristow, M. (1990) The Surgically Denervated, Transplanted Heart. Circulation, 82, 658-660. http://dx.doi.org/10.1161/01.CIR.82.2.658

[12] Kavanagh, T., Yacoub, M., Mertens, D., Kennedy, J., Campbell, R.B. and Sawyer, P. (1988) Cardiorespiratory Responses to Exercise Training after Orthotopic Cardiac Transplantation. Circulation, 77, 162-171.

http://dx.doi.org/10.1161/01.CIR.77.1.162 
[13] Buendia-Fuentes, F., Almenar, L., Ruiz, C., Vercher, J.L., Sánchez-Lázaro, I., Martínez-Dolz, L., Navarro, J., Bello, P. and Salvador, A. (2011) Sympathetic Reinnervation 1 Year after Heart Transplantation, Assessed Using Iodine-123 Metaiodobenzylguanidine Imaging. Transplantation Proceedings, 43, 2247-2248. http://dx.doi.org/10.1016/j.transproceed.2011.05.020

[14] Buendía Fuentes, F., Martínez-Dolz, L., Almenar Bonet, L., Sánchez-Lázaro, I., Navarro Manchón, J., Sánchez-Gómez, J.M., Raso Raso, R., Agüero-Ramón-Llin, J., Sancho-Tello de Carranza, M.J. and Salvador Sanz, A. (2010) Normalization of the Heart Rate Response to Exercise 6 Months after Cardiac Transplantation. Transplantation Proceedings, 42, 3186-3188. http://dx.doi.org/10.1016/j.transproceed.2010.05.056

[15] Prifti, E., Crucean, A., Bonacchi, M., Bernabei, M., Murzi, B., Vincenzo Luisi, S. and Vanini, V. (2002) Early and Long Term Outcome of the Arterial Switch Operation for Transposition of the Great Arteries: Predictors and Functional Evaluation. European Journal of Cardio-Thoracic Surgery, 22, 864-873. http://dx.doi.org/10.1016/S1010-7940(02)00613-9

[16] Rodríguez Puras, M.J., Cabeza-Letrán, L., Romero-Vazquianez, M., Santos de Soto, J., Hosseinpour, R., Gil Fournier, M., Alvarez Madrid, A., González, A., Pérez, P. and Gallego, P. (2014) Mid-Term Morbidity and Mortality of Patients after Arterial Switch Operation in Infancy for Transposition of the Great Arteries. Revista Española de Cardiología, 67, 181-188. http://dx.doi.org/10.1016/j.recesp.2013.06.024

[17] Khairy, P., Clair, M., Fernandes, S.M., Blume, E.D., Powell, A.J., Newburger, J.W., Landzberg, M.J. and Mayer Jr., J.E. (2013) Cardiovascular Outcomes after the Arterial Switch Operation for D-Transposition of the Great Arteries. Circulation, 127, 331-339. http://dx.doi.org/10.1161/CIRCULATIONAHA.112.135046

[18] Deal, B.J. (2011) Late Arrhythmias after Surgery for Transposition of the Great Arteries. World Journal for Pediatric and Congenital Heart Surgery, 2, 32-36. http://dx.doi.org/10.1177/2150135110386251

[19] Bonnet, D., Bonhoeffer, P., Piechaud, J.F., Aggoun, Y., Sidi , D., Planché , C. and Kachaner, J. (1996) Long-Term Fate of the Coronary Arteries after the Switch Arterial Operation in Newborns with Transposition of the Great Arteries. Heart, 76, 274-279. http://dx.doi.org/10.1136/hrt.76.3.274

[20] Bonhoeffer, P., Bonnet, D., Piechaud, J.F., Stümper, O., Aggoun, Y., Villain, E., Kachaner, J. and Sidi, D. (1997) Coronary Artery Obstruction after the Arterial Switch Operation for Transposition of the Great Arteries in Newborns. Journal of the American College of Cardiology, 29, 202-206. http://dx.doi.org/10.1016/S0735-1097(96)00433-0

[21] Bergström, B., Lilja, B., Rosberg, K. and Sundkvist, G. (1986) Autonomic Nerve Function Tests. Reference Values in Healthy Subjects. Clinical Physiology, 6, 523-528. http://dx.doi.org/10.1111/j.1475-097X.1986.tb00785.X

\author{
Abbreviations \\ ASO $=$ arterial switch operation \\ $\mathrm{E}$ :I ratio = expiration inspiration ratio \\ ECG = electrocardiography \\ HRV = heart rate variability \\ TGA $=$ transposition of the great arteries
}

